\title{
Call for a slower approach to health care reform
}

$\mathrm{H}$ ealth care in the United States is in shambles. We justifiably boast of our prowess in high technology, but our measurable standard health care results are among the poorest in the developed world, well below those of Western Europe. Our costs per citizen are almost twice those of Western Europe and remain on a ruinous rising curve. We are not providing adequate primary and preventive care to our large pool of uninsured and poor citizens, who get unnecessarily sick and cost much more to treat in the long run. We are vastly overtreating and overtesting millions of patients, particularly the elderly and those in the last few months of life. Insurance premiums are confiscatory but unnoticed by those who have employer- or government-based insurance. The premiums are destroying our worldwide competitiveness. Smoking, the cause of 30 percent of cancer and much of cardiopulmonary disease, is still a menace, and we have allowed the soft drink industry and the corn lobby through a supine Department of Agriculture to poison our public school meals program with corn products enough to induce an epidemic of obesity and diabetes - all preventable. It seems ridiculous on the surface to propose an expansion of health care services unless we totally change the models of health care delivery and disease prevention that have brought us to this precipice.

Unfortunately, any proposed change of our bankrupt system is a third rail for politicians. Drug companies need profits to create new drugs, but they usually lose money when new drugs are developed because the new drugs fail so often. So they charge what the market will bear for successful drugs and make copycat drugs that they directly market to unsophisticated patients and gullible busy doctors. The executives of insurance and drug companies enjoy huge compensation and are focused on their quarterly stock appraisals instead of their mission. Doctors who do procedures are often adherents of independent fee-for-service medicine - particularly if they own the services. Hospitals charge better-paying insurers to make up for inadequate payers. Great academic hospitals are forced to play every legal billing trick in the accounting playbook in order to remain in the black for clinical services so that they can absorb inevitable losses in biomedical research and teaching. The elderly may deride government, but they are equally prone to shout "Don't touch my Medicare." All of this (and there is much more) amounts to a witches' brew of political hazards for those in the White House and Congress who must find a way out of the mess and still remain in office.

To his credit, President Obama has decided to champion reform, but his timing could not be worse. We are facing a $\$ 9$ trillion accounts deficit at the end of the

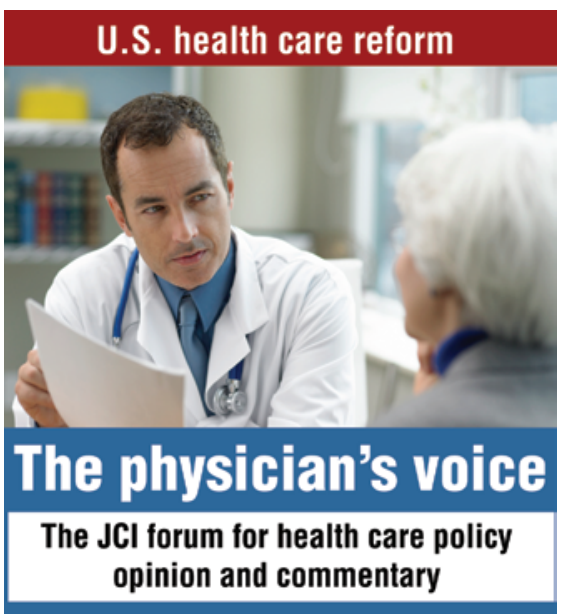

next decade. No one knows whether lenders will be available if we accumulate such a huge deficit. The alternative is rampant inflation. Even if the health care stakeholders were of common mind (which they are not), this is a dangerous moment in which to begin an overhaul of a very large fraction of the economy, the consumers and providers of which are galloping off in all directions. The President is right, of course, when he tells the public that if we do not make necessary changes, the entire system may be imperiled, but he soft-soaps voters when he tells them that reform will be painless, provide portability, and ban rejection from preexisting conditions and cancellations. No one will become bankrupt from illness, nor be required to change insurance policies or physicians. Like Bush, he asks for no sacrifice from average Americans. But unlike Bush, he assigns replacement for every deficit-producing increase in a broken budget to increments in taxes on the rich. He doesn't seem to notice that the ranks of the rich are becoming depleted as incomes decline.
He speaks vaguely about heightened efficiency of care and implies that electronic records represent a near-magical path to solvency but provides no hard data to support his sunny optimism; nor does he seem to recognize that electronic records are hugely expensive to install, difficult to learn, and slowly accepted by most current physician. He lauds the Cleveland and Mayo Clinics, but they are referral-based specialty clinics. The inner-city or rural poor do not go there.

The facts are that we cannot achieve a cost-conscious, efficient health care system that reaches the poor as well as the affluent and preserves our excellence in discovery and technology without undertaking a massive change in our entire medical care culture. We must build a much stronger primary care system in which nurses - backed by experienced physicians-- take far more responsibility. Group practice must dominate medical care, and salaries rather than fee-for-service should be the predominant method of practitioner reimbursement. We need coherent regional medical care in which patients are referred to established centers for highly technical procedures akin to the WAMI (Washington, Alaska, Montana, Idaho) program undertaken by the University of Washington. Reimbursement by insurers, whether public or private, must be reasonable, but it must be tightly managed to prevent the current raid on the US Treasury and private insurance policies. Accordingly, we need much tougher insurance rules. Every insurance policy other than health insurance has a deductible. Absent "skin in the game," insured patients will willingly undergo one useless expensive test after another. If we get to a single nonprofit payer (the executives of which eschew lucullan salaries), we will have to determine the deductible that must be paid by any covered family or individual.

Achievement of these necessary changes will take time. President Obama is a brilliant man and a great educator. He should teach the public about the need for and details of reasonable health care reform while he straightens out the economy. When Americans are clearly going back to work and deficits are beginning to shrink, morale will rise, and he can start us on the long, bumpy road to a decent health care system. I realize, of course, that Demo- 
crats, the party of health care reform, are in a precarious political position because of the failures of the previous administration and may not have enough votes to push through any plan after the elections of 2010. But we are talking about an enor- mous and hugely costly program with a profound impact on our economy and, indeed, our entire future. We simply have to get it right if we are to take it on at all.

\section{David G. Nathan}

Dana-Farber Cancer Institute and Children's Hospital, Boston, Massachusetts, USA. E-mail: david_nathan@dfci.harvard.edu.

J. Clin. Invest. 119:2847-2848 (2009). doi:10.1172/JCI40994.

\section{Healing health care}

y 2018, health care expenditures are expected to consume more than $20 \%$ of US gross domestic product (1). Over the last decade, there has been a marked increase in health care spending without corresponding improvements in longevity or quality of life. In short, we simply are not getting our money's worth, and we need to improve the value of our health care dollar.

Reduce or eliminate direct-to-consumer advertising. My healthy seven-year-old niece complained that her bones were sore and she needed Boniva (once-monthly oral ibandronate). In the United States, health care advertising is pervasive and has become part of the fabric of everyday life. The most dramatic increases in health care spending have been since 1997, the year the FDA relaxed regulation on direct-to-consumer advertising on television. From 1997 to 2007, direct-to-consumer advertising for prescription drugs increased $330 \%$ (2). In 2005, the budget for prescription drug advertising was $\$ 30$ billion. Notably, this cost estimate does not include advertising for hospitals, insurers, devices, and other health-related services, and it does not include the costs of unnecessary visits and testing. Direct-toconsumer advertising of prescription drugs is having long-term consequences on the pharmaceutical industry, steering business strategy toward "lifestyle" drugs and away from the more difficult-to-treat diseases such as heart disease, cancer, and diabetes. Research is needed to devise new strategies for these disorders, and the budget for research should index to health care expenditures. A redirection of the direct-to-consumer advertising budget toward research would be a better investment in our future. Ironically, an additional \$45-\$60 million has been spent this year on advertising for health care reform (3). The winners are clearly the advertising companies, and the losers are those who have to explain to their children what erectile dysfunction is and why drugs are so expensive.

Toss out exclusions for preexisting conditions. Insurance providers would like to screen and exclude those who are ill and those who are at risk of becoming ill, since providing for the healthy is a better business strategy. I am a geneticist, and we now routinely use genetic diagnoses to guide clinical management and predict risk for future disease. Advances in human genetics are obliterating the concept of the preexisting condition, since all human disease has a heritable component. The ability to predict risk for disease is advancing at light speed. Such genetic research can nearly instantaneously be converted to clinical testing, where it usefully predicts risk of disease, the insurers' dream come true. The Genetic Information Nondiscrimination Act (GINA) took a first step toward protecting against insurance discrimination based on genotype (4). Treating a genetic condition is not protected under GINA. There is an increasingly blurry line between an "at-risk" genotype versus early-phase disease that requires therapy to reduce risk. The greatest advances of this decade are deriving from the fruits of the human genome project. Curiously, coverage for genetic testing is still limited, and earlyphase risk reduction therapy is not always covered. Eliminating an insurer's ability to void coverage of a preexisting condition has been extensively discussed in the context of health care reform. The insurance industry is politically mighty; it is up to the public to keep pressure on members of Congress to legislate protection against the preexisting condition exclusion.

Bring bealth information management into the modern era. One of the biggest money pits for our health care dollars is the outdated management of health information. The electronic information age arrived some time ago but left health information behind. Health information is stored in a variety of formats that are often incompatible, ranging from paper to obsolete electronic media. Health care providers do not share information readily with each other. Sharing information is time consuming and a largely uncompensated activity. It is far easier to reorder a test than to request the results from the test that has already been performed. A uniform format for health care information should be established and used. Information management and maintenance should be taken from the control of the health providers and given to organizations with expertise in information management. Patients should control who has access to their personal health information. It should be within a patient's right to authorize or deauthorize access to health information. Patients should be able to readily determine who has accessed their heath information and for what purpose. Health care providers should not "own" patients' health information. Diagnostic testing increasingly relies on imaging, and while I can watch just about anything on YouTube, I frequently cannot view my patients' echocardiograms performed at outside institutions. Having a uniform format would allow ready access and viewing, which would result in better health care, improved quality control, and a reduction in unnecessary testing. It is time for health care information to grow up and at least be as good as iTunes. Health care providers have repeatedly demonstrated an inadequacy in this area, and it seems a striking opportunity for the business community to design and implement a new approach to this problem.

\section{Elizabeth M. McNally}

The University of Chicago, Chicago, Illinois, USA.E-mail: emcnally@uchicago.edu.

J. Clin. Invest. 119:2848 (2009). doi:10.1172/ JCI41037.

1. Centers for Medicare and Medicaid Services. National health expenditure data overview. http:// www.cms.hhs.gov/nationalhealthexpenddata/ 01_overview.asp.

2. Donohue, J.M., Cevasco, M., and Rosenthal, M.B. 2007. A decade of direct-to-consumer advertising of prescription drugs. N. Engl. J. Med. 357:673-681.

3. Campaign Media Analysis Group. http://www. tnsmi-cmag.com/index.asp.

4. Anonymous. 2008. Genetic Information Nondiscrimination Act. HR 493. 110th Congress, 2nd sess. Congr. Rec. (Dly. Ed.). 154:D661. 